\section{Face e polidez linguística em reclamações online: uma análise sob o viés pragmático}

Face and linguistic politeness in online complaints: an analysis under the pragmatic bias

Luana Lisboa BARRERE (UFES) lisbluana@hotmail.com

\title{
00000000000
}

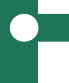

BARRERE, Luana Lisboa. Face e polidez linguística em reclamações online: uma análise sob o viés pragmático. Entrepalavras, Fortaleza, v. 7, p. 383-405, jan./jun. 2017.

Resumo: Neste artigo apresentamos um estudo sobre reclamações postadas no site brasileiro ReclameAQUI e o nosso objetivo consiste em verificar como ocorre o processo de preservação e perda da face através do uso ou da violação dos recursos linguísticos de polidez no processo de interação entre consumidores e fornecedores das empresas reclamadas. Para tanto, adotaremos a teoria da polidez proposta por Brown e Levinson (1987), utilizando as estratégias de polidez positiva e negativa apresentadas por esses autores, além das máximas de Leech (1983), em diálogo com a noção de face de Goffman $(1967 ; 1980)$. De acordo com os resultados das análises, chegamos à conclusão de que os consumidores violaram mais os recursos de polidez que os representantes das empresas, o que resultou em um número maior de perda de faces dos clientes do que desses representantes.

Palavras-chave: Pragmática. Polidez. Face. ReclameAQUI. 
v. 7 (1) 383-405 jan/jun 2017

\section{Introdução}

A linguagem é o produto da interação verbal, e esta, por sua vez é a responsável pela construção de realidades e relações interpessoais, as quais se constituem por meio de qualquer troca verbal, como conversas, e-mails, discussões, confissões etc. A linguagem é uma atividade tão comum para as pessoas que muitas delas não se dão contam dos diversos fenômenos que podem emergir dos processos interacionais. Todavia, ainda que seja uma prática comum e corriqueira, não se pode pensar que a linguagem não é complexa ou um objeto irrelevante de ser estudado, pois ela tem um papel fundamental nas interações verbais, sejam face a face, virtualmente ou à distância, possuindo uma sistematicidade, normas e regras que orientam "invisivelmente" o comportamento discursivo e até corporal dos participantes da interação. Essa ordem e sistematicidade nos processos de interação verbal se manifestam por meio da postura corpórea dos locutores e, sobretudo, pela postura verbal que assumem de acordo com a maneira como ocorrem as trocas de turno conversacional ${ }^{1}$, pelas marcas linguísticas e escolhas lexicais, pelo uso de polidez, ou ausência desta etc.

Dessa maneira, os participantes de um evento comunicativo se engajam e buscam ordenar o processo de interação equilibrando e controlando suas falas para que a comunicação ocorra de modo menos ameaçador possível, recorrendo, portanto, a vários procedimentos de validação interlocutória. Os interlocutores, portanto, se envolvem, falam de algo ou alguém, para alguém, em um determinado espaço e tempo, estabelecendo uma trama completa e complexa, na qual irá constituir-

${ }^{1}$ No âmbito da linguística textual, o turno é compreendido como o momento de fala, isto é, um período de tempo mantido entre e pelos interlocutores em uma interação, até que cada um assuma sua vez de dizer (GALEMBECK, 1993). 
se o contexto sociointeracional, o qual, por sua vez, rege e determina os eventos comunicativos, o que pode, muitas vezes, colocar a imagem social dos participantes em risco. É em virtude desses confrontos envolvendo a imagem social das pessoas que surge a noção de face, uma vez que ao interagir uns com os outros, os participantes se expõem, estando suscetíveis a constantes pré-julgamentos. Nessa esteira, a face, segundo Goffman $(1967 ; 1980)$, trata-se de uma imagem pública que as pessoas têm a preocupação de apresentar, preservar e manter, agindo muito cuidadosamente no momento da interação, visto que muitas coisas são postas em jogo quando falamos, circunstância que impede as pessoas de agirem de qualquer maneira em determinadas situações e contextos de comunicação. A preocupação com a manutenção da face, ou seja, com a preservação da autoimagem, não é algo estranho, pelo contrário, é um processo natural, pois as imagens que passamos, sejam elas efetivas ou não (máscaras), nos constituem enquanto seres sociais, uma vez que tais imagens exercem grande influência no momento em que estamos construindo nossas relações com outras pessoas.

No nível pragmático, a linguagem é entendida como o principal elemento que constitui os atos de fala, dos quais os participantes, ao fazerem uso de alguns deles (pedir, reclamar, confessar, declarar etc.), produzem efeitos de sentido que direcionam e regulam as imagens que os participantes constroem um do outro. Sendo assim, além da discussão sobre a necessidade de preservação da imagem individual, a teoria da polidez linguística de Brown e Levinson (1987), conjugada às máximas de Leech (1983), assume um papel importante na análise do corpus deste trabalho, visto que se relaciona fortemente com a noção de face de Goffman (1967; 1980), e com a intenção de avaliar se é considerado que a polidez, enquanto um sistema estratégico de comportamento linguístico dos quais os indivíduos fazem uso, é utilizada com o objetivo de evitar situações de confronto em interações que podem ameaçar e romper a face.

A partir dessa prévia discussão, analisaremos como os clientes e os representantes das empresas articularam suas falas em um ambiente virtual de interação, que é o website brasileiro de reclamações de serviços e produtos diversos ReclameAQUI, observando como esses participantes utilizaram ou cometeram violação dos recursos de polidez e como isso acarretou na preservação ou perda das faces envolvidas. 
v. 7 (1)

383-405

jan/jun

\section{7}

\section{Pragmática: uma breve discussão}

Recentemente, há estudos que se movimentam em duas direções quando o assunto é a formulação de uma teoria pragmática, mas ambos sentidos se centram no uso, e esse termo "uso", por sua vez, comporta várias definições, bem como o próprio termo "pragmática".

A pragmática linguística está filiada à pragmática filosófica, isto é, está vinculada à filosofia da linguagem e também aos estudos da semiótica, por meio dos estudos dos signos e da relação que cada signo estabelece com outros signos. A partir do estudo dos signos, houve três desdobramentos que deram surgimento à semântica, que estuda o signo em sua relação com os objetos; a sintaxe, que estuda as relações do signo com outros signos e, por fim, o nível pragmático, que se ocupou em estudar a relação do signo com seu usuário. Com esses desdobramentos, a linguagem vai se distanciando da concepção clássica aristotélica, e passa a ser vista não como um reflexo do mundo, nem da realidade, mas sim, de mediação, pois ela é quem cria as coisas, mas isso só é possível quando há um falante que faz uso dela para significar o mundo e seus objetos:

Quando a linguagem é adquirida, o que se adquire não é pura e simplesmente uma língua, com suas regras especificamente lingüísticas, mas todo um sistema de práticas e valores, crenças e interesses a ele associados. É nesse sentido que podemos falar da aquisição de uma pragmática (MARCONDES, 1992, p. 41, grifo nosso).

Com base nesse argumento, é possível afirmar que a pragmática é o estudo do contexto e dos usos linguísticos que os indivíduos efetuam nos processos de interação verbal, dentro de um determinado evento comunicativo, e, sendo assim, é a partir daí que a pragmática se ocupa em estudar não apenas o uso, mas também o usuário e o contexto sociointeracional, revelando como os falantes de uma determinada língua fazem suas escolhas linguísticas em determinadas situações de comunicação, de modo que seus propósitos e atos de fala produzam determinados efeitos de sentido para os outros participantes. Nesse contexto, surge a necessidade de discutirmos a teoria da polidez e a noção de face, uma vez que o modo como falamos, para quem estamos falando e do que falamos são fatores comunicacionais que colocam nossa imagem em risco a todo o momento. 
A linguagem possui dois papéis fundamentais nas interações sociais, pois, na medida em que ela constrói nossas imagens sociais, ela também é responsável pela preservação dessas imagens ou até mesmo pela ruptura delas. Faz-se necessário, portanto, discutirmos sobre conceitos importantes como os de face, que consiste nessa imagem social, e de polidez, que é a maneira como podemos falar certas coisas a fim de manter a boa imagem. Assim, o estudo dessas noções nos permitirá saber da importância desses dois elementos nas relações que as pessoas estabelecem umas com as outras.

\section{A teoria da polidez e o conceito de face}

A polidez existe por causa da face, pois é a responsável pela preservação desta e, desse modo, face e polidez estão fortemente relacionadas, circunstância que nos convida a realizar uma abordagem sobre ambas as noções de maneira integrada. Nas próximas seções, veremos do que tratam esses conceitos e como irão funcionar em nossa análise.

Face

Nos anos 70, os estudos da polidez de Brown e Levinson, inscritos no âmbito da Sociopragmática, se ancoraram nas pesquisas de Erving Goffman sobre os estudos da face. Goffman (1967), ao perceber que os falantes, em situações de interlocução, inevitavelmente buscam manter uma face que é construída inconscientemente e naturalmente, considerou a face como uma imagem social que uma pessoa reclama para si mediante o que os outros presumem que ela seja dentro de um momento específico de interação.

A face é o que as pessoas têm de mais íntimo e particular, mas que ao mesmo tempo é apenas um empréstimo feito pela sociedade. Nas interações verbais, a utilização de determinados atos de fala pode comprometer as faces envolvidas, motivo que conduz as pessoas a utilizarem certas estratégias linguísticas para evitar seu rompimento e também os confrontos que podem surgir no momento da interação.

Os indivíduos não possuem apenas uma face, visto que desempenham vários papéis na sociedade, o que exige que se construa mais de uma imagem pública. Existem dois grandes tipos de face, que Brown e Levinson (1987) chamaram de face positiva e a face negativa. A primeira relaciona-se à necessidade de aceitação que os indivíduos 
v. 7 (1)

383-405 jan/jun 2017

têm nas relações, ou seja, o desejo de ser aprovado e aceito pelas outras pessoas e a segunda, ao desejo que todo o indivíduo tem de não sofrer imposições, nem coerções de suas atitudes, isto é, a vontade de liberdade de ação e a necessidade de independência, que se vincula à noção de território pessoal. Nesse sentido, as faces e o grau de ameaças a ela também variam de acordo com os papeis sociais que os participantes envolvidos em uma determinada situação de comunicação desempenham:

Os locutores se representam uns diante dos outros de determinada maneira. Primeiramente, em nossa vida cotidiana, nós nos representamos (processos de figuração) diante dos outros de formas bastante variadas: por ex: uma mulher ora se representa como mãe, ora como esposa, ora como amiga, ora como profissional, ora como esportista etc. Em cada uma dessas situações, agimos de forma diferente, inclusive - ou sobretudo - em termos de linguagem $(\mathrm{KOCH}$, 1992, p. 107).

As noções de face positiva e face negativa propostas por Brown e Levinson às vezes não são compreendidas com facilidade, o que pode gerar certa confusão conceitual. Assim, na tentativa de compreendermos melhor essas noções, tomamos empréstimo mais uma vez das palavras de Koch (1992, p. 107), ao apontar que:

Cada indivíduo tem uma face externa ("positiva") - o modo como deseja ser visto pelos outros - que gostaria de ver preservada. Por outro lado, possui também uma face interna ("negativa"), seu território íntimo, que não gostaria de ver invadido (grifo nosso).

Goffman (1980), por sua vez, revela, por um lado, que além da necessidade de construção de faces, os indivíduos buscam preservá-la, o que faz com que desenvolvam uma orientação defensiva. Por outro lado, os indivíduos também agem a favor da preservação da face do outro, o que corresponde à orientação protetora, devido ao fato de que os atos de ameaça à face (Face Threatening Act - FTA) podem estar presentes em quaisquer situações de interação, e é por isso que

[...] Em geral, as pessoas cooperam (e pressupõem a cooperação mútua) na manutenção da face na interação, sendo essa cooperação baseada na vulnerabilidade mútua da face. Isto é, normalmente, a face de qualquer um depende da manutenção da face de todos os outros e, como se pode esperar que as 28 pessoas defendam suas faces quando ameaçadas, e, ao defender suas próprias faces, ameaçam a face dos outros, geralmente é de interesse de cada participante manter a face do outro, isto 
é, agir de forma a assegurar aos outros participantes que o agente está atento às pressuposições relativas à face ameaçada (BROWN; LEVINSON, 1987, p. 61)².

Assim sendo, a polidez surge com o objetivo de manter e resgatar as faces perdidas. Na próxima subseção apresentaremos e discutiremos do que se trata a polidez, que consiste em um fenômeno linguístico de grande importância, pelo fato de determinar a ordem e o bom tratamento entre os indivíduos em suas relações sociais.

Teoria da polidez

Na linguística, existem muitas noções de polidez e por isso acreditamos ser válido apresentarmos algumas delas para que possamos montar um quadro panorâmico, embora seja a partir da teoria de Brown e Levinson (1987) que fundamentaremos nossa análise.

A polidez, como apontamos anteriormente, está relacionada a processos de elaboração e preservação da face e consiste em uma atitude duplamente orientada que visa organizar e manter a cordialidade no tratamento que os indivíduos oferecem uns aos outros em certas situações de comunicação. A partir dessa perspectiva, a polidez pode tanto ser entendida como o "interesse correlativo ao reconhecimento da importância do nível da relação interpessoal" (MAINGUENEAU; CHAURADEAU, 2004, p. 81), como também uma espécie de conduta, ou melhor, de uma estratégia linguística adotada pelos falantes, a qual pode apresentar:

[...] certa deferência para com outrem, o reconhecimento de sua existência e valor. É por essa razão que se costuma associar polidez à civilidade, e a sua ausência à incivilidade, que é uma forma de violência (LA TAYLLE, 2001, p. 98).

São muitas as concepções de polidez que podemos encontrar nos estudos linguísticos, mas concordamos com Oliveira (2005, p. 1-2, grifo nosso), ao salientar que esse fenômeno, embora possa ter várias conceituações, "envolve o uso de estratégias verbais e não verbais a fim de manter a interação livre de problemas".

\footnotetext{
2 "[...] In general, people cooperate (and assume each other's cooperation) in maintaining face in interaction, such cooperation being based on the mutual vulnerability of face. That is, normally everyone else's being maintained, and since people can be expected to defend their faces if threatened, and in defending their own to threaten others' faces, it is in general in every participant's Best interest to maintain each others' face, that is to act in ways that assume the other participants that the agent is heedful of the assumptions concerning face given under above".
} 
v. 7 (1)

383-405

jan/jun

2017

Adotando-se a noção de polidez enquanto estratégia verbal, consideramos que os trabalhos de Brown e Levinson contemplam de maneira mais abrangente qualquer estudo sobre esse tema. Ao sistematizarem e explicarem as estratégias de polidez que são e/ou podem ser utilizadas em qualquer situação de comunicação, os referidos autores constataram que o fenômeno é universal. A polidez, segundo os autores, é uma estratégia de processamento textual que se dá por meio uso de determinadas estruturas linguísticas (sintáticas, semânticas, discursivas) em certos contextos específicos de interação, a fim de que sejam atenuados os efeitos de um ato ameaçador da face (BROWN; LEVINSON, 1987).

O mencionado termo estratégia é usado por eles, devido ao fato de ser um termo que remete à cognição, isto é, um elemento da racionalidade que engloba atitudes conscientes e também inconscientes, o que significa dizer que os indivíduos sabem que é necessário amenizar os riscos de ameaça às faces envolvidas, porém, as escolhas estratégicas são feitas com tanta rapidez e naturalidade que esse processamento nem sempre acontece de maneira totalmente consciente.

Na teoria de Brown e Levinson (1987), há algumas intenções comunicativas envolvidas no processo de interação que são utilizadas para minimizar o grau de ameaças à face, como por exemplo, o desejo de se comunicar de forma eficiente e precisa, ou o próprio desejo de manter, ao máximo, a face do interlocutor preservada. Diante da necessidade de salvar as faces e atenuar possíveis ameaças, existem estratégias de polidez que podem ser utilizadas de variadas maneiras, a saber:

1. de forma direta, sem atitudes de reparo;

2. com polidez positiva direcionada à face positiva do interlocutor, de modo a demonstrar que existe, em maior ou menor grau, interesse do locutor nas mesmas coisas que o ouvinte (interesse que se fundamenta no desejo de aceitação social);

3. com polidez negativa, na qual o locutor aponta para satisfazer a face negativa de seu interlocutor, contanto que suas necessidades básicas de preservação de território e de autodeterminação não sejam violados;

4. de maneira sutil, ou seja, de forma indireta;

5. não executá-la (BRONW; LEVINSON, 1987). 
Assim como vimos que existem face positiva e negativa, vemos, como propõem Brown e Levinson, que há, também, estratégias de polidez positiva e de polidez negativa, em que a face positiva está para a polidez positiva, enquanto a face negativa está para a polidez negativa. Sendo assim, é com o foco nas estratégias de polidez do tipo positiva e negativa que nossa análise será efetuada e, para tanto, é necessário apresentar essas estratégias.

Estratégias de polidez positiva

Segundo Brown e Levinson (1987), a polidez positiva é usada pelo locutor para manter a face positiva do seu interlocutor no intuito de se aproximar deste, ganhando aceitação e admiração. Desse modo, as estratégias de polidez positiva visam diminuir a distância social, envolvendo os participantes de modo mais íntimo. A seguir, listamos as que acreditamos que sejam as mais importantes para esta discussão:

1. Demonstre interesse, aprovação e simpatia pelo interlocutor;

2. Intensifique o interesse pelo outro;

3. Adote marcas de identidade de grupo;

4. Considere os interesses, vontades e necessidades do interlocutor;

5. Procure concordância, conciliação;

6. Evite desentendimentos;

7. Inclua o ouvinte na interação;

8. Explicite reciprocidade;

9. Prometa, ofereça coisas;

10. Forneça benefícios ao ouvinte (simpatia, cooperação etc.) (BROWN; LEVINSON, 1987).

Estratégias de polidez negativa

As estratégias de polidez negativa, por sua vez, são usadas com o objetivo de estabelecer um tratamento mais distanciado, evitando, assim, as imposições e invasões às faces dos participantes envolvidos na interação. Assim, como fizemos anteriormente, abaixo apresentamos as estratégias mais importantes: 
v. 7 (1)

$383-405$

jan/jun

2017

1. Minimizar a imposição;

2. Mostrar respeito;

3. Ser indireto;

4. Desculpar-se;

5. Impessoalizar o discurso, evitando o uso dos pronomes pessoais do caso reto eu e você;

6. Agir como se estivesse em débito com o interlocutor (BROWN; LEVINSON, 1987).

Máximas da polidez

Até o momento, vimos no que consistem as estratégias de polidez positiva e negativa. Devido à importância desse modelo constituído por Brown e Levinson (1987), Leech (1983) aprofundou os seus estudos, nos quais buscou aprimorar os princípios conversacionais, aproximando os conceitos tradicionais da retórica aos da pragmática, no que diz respeito às situações de comunicação. Com isso, o estudioso compreendeu que a polidez trata-se de uma norma de comportamento que pertence a uma determinada comunidade, a qual se manifesta tanto no conteúdo do que se quer dizer, quanto na maneira como os participantes se comportam para apresentarem o que querem dizer. É nessa esteira que Leech (1983) estabelece as máximas da polidez, a saber:

1. Máxima do tato:

a. Minimize o custo do outro.

b. Maximize o benefício do outro.

2. Máxima da generosidade

a. Minimize o benefício de si próprio.

b. Maximize o custo a si próprio.

3. Máxima da aprovação

a. Minimize a aprovação do outro.

b. Maximize a honra do outro.

4. Máxima da modéstia

a. Minimize seu orgulho, sua vaidade.

b. Maximize sua modéstia.

5. Máxima da concordância

a. Minimize a desavença entre as pessoas.

b. Maximize a concordância entre as pessoas. 
6. Máxima da simpatia

a. Minimize a antipatia.

b. Maximize a simpatia.

Seja por meio das estratégias de polidez positiva e negativa e/ou por meio das máximas de polidez, é evidente que a vontade de evitar as ameaças à face dos participantes na interação é o objetivo principal que aparece nesses postulados. Se pensarmos em situações comunicativas específicas que podem gerar confrontos que altos graus de ameaças às faces das pessoas envolvidas, como um espaço virtual para reclamações por escrito, por exemplo, podemos inicialmente questionar: reclamar pode prejudicar as faces dos participantes? As reclamações dos clientes e as respostas das empresas tenderiam a violar ou a respeitar as estratégias e máximas de polidez? Por qual motivo haveria uso e/ou violação desses recursos de polidez?

Essas perguntas dão fôlego a este estudo. Sendo assim, tentaremos respondê-las ao término da nossa análise. Todavia, antes de analisarmos as reclamações escolhidas, é importante abordarmos sobre o site ReclameAQUI, a fim de situar o nosso trabalho.

\section{O site ReclameAQUI}

O ReclameAQUI é um site brasileiro fundado por quatro sócios, que tem o objetivo de abrir um espaço virtual para publicação de reclamações sobre compras de produtos, atendimento e prestação de serviços diversos. Para que os clientes possam ter suas reclamações publicadas, é necessário somente cadastrar os dados pessoais, e o mesmo também se aplica às empresas, que precisam possuir cadastro para que apareçam na listagem do site, garantindo, assim, o acesso e o atendimento entre ambas as partes, que têm a identidade pessoal preservada pela política de privacidade do ReclameAQUI.

Assim que a reclamação é publicada, a empresa reclamada é comunicada e a mensagem é transmitida via e-mail com todos os detalhes do problema em questão. O ReclameAQUI não permite participações anônimas ou registradas como apelidos, pois as reclamações são assinadas e estão sob responsabilidade dos interessados. Antes da publicação das mensagens dos consumidores, o conteúdo passa por uma avaliação por parte de uma equipe do site, pois sua política não permite conteúdo ofensivo na redação dos usuários. Após terem suas 
v. 7 (1)

383-405

jan/jun

2017

reclamações publicadas e eventualmente respondidas, os consumidores notificam ao site se o problema foi resolvido ou não, além de ter o direito a réplicas e ao final mostrar suas opiniões sobre a resposta obtida pela empresa em questão. E para fins de segurança, as mensagens dos usuários ficam armazenadas em um banco de dados e todo o conteúdo público do site é disponibilizado automaticamente pelo Google e outros buscadores, todavia, os dados pessoais não são revelados.

\section{Reclamações online: uma proposta de análise}

Reclamar pode ser um ato de fala ameaçador da face, podendo ameaçar, em maior grau, a face do interlocutor, pela grande possibilidade de invasão direta ao seu território pessoal. Ao analisarmos algumas reclamações publicadas no ReclameAQUI, observamos um rico material que nos permitiu promover uma análise dos processos de preservação e de perda da face que está diretamente relacionado ao uso e/ou à violação dos recursos de polidez nas reclamações publicadas.

Na seção reclamações respondidas do referido site, encontramos reclamações realizadas pelos clientes que já obtiveram resposta das empresas solicitadas. Como nosso objetivo é analisar os processos de construção e perda de face via polidez na interação, essa seção possui conteúdos que melhor correspondem à nossa proposta de estudo. Assim, selecionamos seis textos (três de clientes e três dos fornecedores das empresas), publicados entre os meses de maio a junho do ano de 2015, e os articulamos da maneira que está no próprio site, ou seja, primeiramente a reclamação e, sem seguida, a resposta. Para preservar as identidades de todos os participantes envolvidos, chamamos cada cliente de $\mathrm{X}$, cada representante empresarial de $\mathrm{Y}$ e empresas avulsas (citadas, mas que não foram reclamadas) de W.

\section{Análise 1}

A reclamação a seguir trata-se da insatisfação de um cliente pela má qualidade no sinal de um pacote de TV paga oferecido por uma empresa de telecomunicações. Além desse motivo, o cliente questiona $\mathrm{o}$ atendimento e posicionamento da empresa frente ao problema:

(1) "Boa noite!!

Estou extremamente insatisfeita, volta e mai eu fico sem sinal em minha TV. Essa semana tive o desprazer de ter 
esse problema duas vezes. Quando ligo pra resolver além do péssimo atendimento do 10621, agendam geralmente para o dia seguinte. Acham que estamos sempre a disposição deles. Hoje liguei o atendente Y me destratou, fez eu ficar muito nervosa pois não queria passar os procedimentos para mim alegando que era somente com o titular mesmo eu dizendo que já havia feito o mesmo procedimento sem a presença do meu esposo(titular). No final das contas ele não resolveu nada e ainda agendou para o dia seguinte detalhe que eu estava ligando as $6 \mathrm{~h}$ da manha de hoje e ele agendou para mais de $24 \mathrm{~h}$ depois ou seja se eu quiser que fique em meu serviço mais de $24 \mathrm{H}$. Liguei na mesma hora para outra atendente e ele a reagendou para o mesmo dia ou seja hoje de 8 as ooH (não é o ideal para mim). Meu receio é que não venham coisa nenhuma pois das outras vezes agendaram para esse horário e não vieram. Estou muito impressionada com a falta de respeito e consideração para o consumidor. Quero que resolvam o quanto antes ou penso em mudar de operadora que pelo menos me trate com dignidade e respeito. Se não vierem resolver meu problema hoje vou procura a empresa $\mathrm{W}$. Aguardo uma solução URGENTE PARA MEU CASO."

Em seguida, a resposta da empresa a essa reclamação:

(2) "Olá, Cliente X!

Conforme nosso contato por telefone em 06/06/2015, informamos que prestamos os devidos esclarecimentos sobre a mensagem recebida. Aproveitamos para solicitar que avalie este atendimento através do site Reclame AQUI. É importante o seu retorno para que possamos através da sua opinião, aprimorarmos nosso atendimento e os serviços prestados. Caso tenha qualquer dúvida, permanecemos à disposição através dos nossos canais oficiais de atendimento, onde você poderá obter soluções mais ágeis.Fale Conosco: (site da empresa Y). Atendimento $24 \mathrm{hs}-7$ dias por semana? Prazo para retorno em até 6 horas.

Atenciosamente, Empresa Y". 
v. 7 (1)

383-405

Podemos observar que o consumidor em questão viola várias máximas e estratégias de polidez positiva, ao intensificar a forma ilocucionária do ato de reclamar. No trecho inicial em que diz "Estou extremamente insatisfeita, volta e mai eu fico sem sinal em minha TV. Essa semana tive o desprazer de ter esse problema duas vezes", o cliente viola a máxima da simpatia, ao maximizar sua apatia e insatisfação pelo serviço prestado, marcado, sobretudo, pela utilização do advérbio "extremamente", que reforça e acentua seu comportamento hostil, além de também romper com a máxima da concordância e da estratégia de polidez positiva evite desentendimentos, provocando uma aparente desavença com seu interlocutor. No excerto que vem a seguir "Quando ligo pra resolver além do péssimo atendimento do 10621, agendam geralmente para o dia seguinte. Acham que estamos sempre a disposição deles", o cliente continua violando essas mesmas máximas e estratégia de polidez mencionadas, denotando falta de cordialidade e respeito a seu interlocutor, criticando, de um modo aparentemente debochado, a presteza do atendimento que lhe foi oferecido.

Ao final, no trecho "Quero que resolvam o quanto antes ou penso em mudar de operadora que pelo menos me trate com dignidade e respeito", ainda que o verbo "querer" esteja na forma do presente do indicativo e não no imperativo, a expressão denota imposição e mando, o que rompe com a estratégia de polidez negativa minimizar a imposição, ao ordenar que o problema seja resolvido de maneira rápida, ameaçando em mudar de operadora, caso essa exigência não seja atendida. Ao finalizar a reclamação dizendo "Se não vierem resolver meu problema hoje vou procura a empresa W". Aguardo uma solução URGENTE PARA MEU CASO.", o cliente ameaça novamente a empresa reclamada, continuando a exigir soluções, na violação das máximas e estratégias acima mencionadas. Além disso, o que chama a atenção neste trecho é o uso da fonte em caixa alta, o que dá impressão de que o cliente está gritando e/ou falando em voz altiva, reforçando, então, a ordem de solução para o seu caso. Por tantos rompimentos com as máximas e estratégias de polidez (tanto negativa e positiva), notamos que este cliente não se preocupou em preservar sua face. Como hipótese, podemos dizer que este consumidor não preservou sua face por três principais motivos: o primeiro, pelo insucesso dos contatos anteriores que manteve com a empresa e o segundo, pelo comportamento desse cliente que possivelmente apresentou polidez nesses contatos anteriores à reclamação publicada e o terceiro motivo se relaciona ao fato de ser uma reclamação por meio virtual, que não revela 
a identidade do consumidor, o que oferece mais liberdade na escrita. Com isso, podemos inferir que esse consumidor usou esses motivos em favor da sua causa, para garantir que seu problema conquistasse a atenção devida.

No caso do representante da empresa, que respondeu a reclamação feita, ao contrário do cliente, buscou preservar sua face, usando algumas estratégias de polidez e respeitando muitas máximas. Podemos perceber isso no início de sua resposta, quando cumprimenta o consumidor com "Olá, cliente x". É interessante destacar o uso do "Olá" como um modo saudação amistoso e próximo, o que marca o uso da estratégia de polidez positiva demonstre interesse, aprovação e simpatia pelo interlocutor, pois aparentemente tenta estabelecer um contato amigável usando essa saudação, haja vista que, em situações de comunicação como essa que tendem a ser mais formais e conflituosas, existe uma recorrência pela utilização de expressões de tratamento formalizadas, que distanciam o locutor do seu interlocutor, como "prezado cliente", "caro cliente", "Sr. cliente", etc.

No trecho que segue "informamos que prestamos os devidos esclarecimentos sobre a mensagem recebida. Aproveitamos para solicitar que avalie este atendimento através do site Reclame AQUI", o representante da empresa usa estratégia de polidez positiva considere os interesses, vontades e necessidades do interlocutor, por demonstrar interesse pelo problema do cliente, utilizando, concomitantemente, a máxima da generosidade, minimizando o benefício de si próprio, ao pedir que o serviço fosse novamente avaliado, valorizando os interesses e a possível avaliação do cliente sobre a empresa.

O representante se mantém atencioso por continuar utilizando a estratégia de polidez positiva acima mencionada no trecho "É importante o seu retorno para que possamos através da sua opinião, aprimorarmos nosso atendimento e os serviços prestados", e, fazendo isso, mostra a importância da opinião do cliente sobre a empresa, o que também revela o apelo pela máxima da concordância uma vez que, ao dar crédito à possível opinião do consumidor, mesmo sem saber se será positiva ou negativa, o representante tenta, assim, atenuar outros possíveis confrontos. Todavia, ainda que este representante tenha respeitado tantas máximas e usado estratégias de polidez, ele viola a máxima da quantidade, a qual prediz que a informação deve ser oferecida na quantidade necessária, não sendo muita, nem pouca (GRICE, 1982) ${ }^{3}$. Sendo assim, este participante

\footnotetext{
${ }^{3}$ Ainda que estejamos usando as máximas propostas por Leech, é interessante valer-
} 
v. 7 (1)

383-405

jan/jun

2017

foi muito breve e vago na informação prestada, não respondendo de maneira esclarecedora à reclamação do cliente por apresentar brevidade e vaguidão em sua resposta.

Finalizando a resposta, o representante da empresa reclamada novamente tenta aproximar-se do cliente e valorizar seus interesses, colocando-se à inteira disposição, na disponibilização de um site para contato, o que mostra aparente presteza e preocupação em solucionar os transtornos causados pela empresa. Vemos isso no trecho "Caso tenha qualquer dúvida, permanecemos à disposição através dos nossos canais oficiais de atendimento, onde você poderá obter soluções mais ágeis. Fale Conosco: (site da empresay)", em que o representante sustenta o uso das estratégias de polidez positiva já vistas até então e também das máximas da simpatia, generosidade, concordância e do tato, considerando que parece haver uma tentativa de maximizar os benefícios em favor do outro, que neste caso seria a solução rápida do problema. Mesmo não tendo respeitado a máxima da quantidade, como foi visto anteriormente, podemos dizer que o interlocutor obteve êxito na preservação da sua face positiva e negativa, ao contrário de seu locutor, que as negligenciou.

Análise 2

Esta reclamação diz respeito à compra de um produto de um tipo de calçado feita online, que não chegou no prazo previsto pela empresa ao cliente. Além da demora na entrega, o cliente questiona o modelo e a qualidade do produto, solicitando sua troca:

(3) Pra começar, comprei um tênis na empresa Y e paguei o frete para receber o produto em até 3 dias úteis. Porém, o tênis chegou após 5 ou 6 dias úteis, o prazo normal de entrega. Tive que solicitar a devolução do frete. Depois que o tênis chegou, o modelo não me agradou como eu imaginei e solicitei a troca via postagem em agência dos Correios. No momento da solicitação, foi informado que eu receberia um e-mail dos empresa $\mathrm{W}$ com as orientações para a postagem. Solicitei a troca por volta do dia 29/05 e até hoje (05/06) não recebi nenhuma orientação para postagem. Enviei um e-mail para email da empresa Y questionando, e este foi devolvido por

nos, neste momento, desta máxima proposta por Grice (1982), uma vez que nos esclarece como os falantes podem falar mais do que o necessário ou também menos, marcando, da mesma maneira, a violação dessa máxima. 
que a caixa de entrada estava cheia. Como pode uma empresa desse porte não receber e-mails porque a caixa está lotada?? Venho tentando contato via chat também, mas ninguém me atende. Enfim, a empresa Y perdeu muito a qualidade. Já fiz várias compras no site e nunca tinha tido problema nenhum, agora parece que eles não estão dando a mínima para o cliente. Com certeza terão um cliente a menos se não resolverem meu problema logo.

Em seguida, a resposta:

(4) Olá cliente X,

Boa Tarde!

Primeiramente, pedimos as nossas sinceras desculpas pelo ocorrido e aproveitamos também a oportunidade para agradecer o apontamento da situação em questão, pois vamos apurar e identificar a origem do erro e aperfeiçoar todos os procedimentos para que não haja uma nova ocorrência. Conforme contato realizado, esclarecemos a situação e geramos uma solicitação de postagem, sendo esta enviada ao seu e-mail para que possamos prosseguir com a sua solicitação de troca. Seu atendimento a partir deste momento tornar-se personalizado, pois como no esporte o objetivo é a superação, nosso intuito é minimizar sua insatisfação. Pedimos por gentileza de deixar a RECLAMAÇÃO NO SITE RECLAME AQUI EM ABERTO ATÉ QUE TUDO SEJA FINALIZADO. Sempre que precisar, estaremos à sua inteira disposição.

Atenciosamente,

Empresa Y.

Este cliente inicia sua reclamação descrevendo o problema com o produto, e, até então, não há ênfase do seu ato ilocucionário de reclamar. Entretanto, ao dizer "Solicitei a troca por volta do dia 29/05 e até hoje (05/06) não recebi nenhuma orientação para postagem" o cliente inicia sua reclamação, expondo desaprovação no que diz respeito à qualidade do atendimento da empresa devido à falta de atenção acerca do que deveria fazer com a postagem de seu produto. Assim sendo, o cliente 
v. 7 (1)

383-405

rompe com a máxima da aprovação, sobretudo no trecho a seguir: "Como pode uma empresa desse porte não receber e-mails porque a caixa está lotada??". Percebemos que nessa fala o cliente continua a expor sua insatisfação pelos serviços da empresa, culminando na violação da máxima da aprovação no trecho final da reclamação: "[...] a empresa Y perdeu muito a qualidade [...] nunca tinha tido problema nenhum, agora parece que eles não estão dando a mínima para o cliente.".

Além de manter o rompimento com a máxima referida acima, o cliente também viola as estratégias de polidez negativa mostrar respeito e polidez positiva demonstre interesse, aprovação e simpatia pelo interlocutor, uma vez que desqualifica os produtos e os serviços prestados, além de criticar a falta de atenção da empresa pelo problema causado, o que, por conseguinte, acarreta um tratamento hostil. Por fim, ao encerrar a reclamação, afirmando "Com certeza terão um cliente a menos se não resolverem meu problema logo", o cliente invade a face do seu interlocutor de maneira muito mais hostil e agressiva, rompendo com a estratégia de polidez negativa minimizar a imposição, pois exige da empresa rapidez em resolver o problema exposto, além de também violar a máxima do tato, quando ameaça deixar de consumir os produtos da empresa, maximizando a perda de benefícios da empresa com tal desistência.

O representante da empresa em questão, por sua vez, apresenta um comportamento ambivalente, à medida que percebemos que utiliza estratégias de polidez positiva e as máximas, ao mesmo tempo em que também as viola. Veremos, então, como esse participante faz esse movimento de preservar sua face até um momento, mas perde-a depois.

Inicialmente, bem como na análise 1 , o representante usa o cumprimento "Olá", ao invés de um tratamento mais formalizado e distanciado, o que também marca o uso máxima de simpatia, por tentar uma aproximação ao cliente de um modo mais amigável. Ao dizer "[...] pedimos as nossas sinceras desculpas pelo ocorrido e aproveitamos também a oportunidade para agradecer o apontamento da situação em questão”, o representante da empresa reclamada faz uso da estratégia de polidez negativa desculpar-se, ao pedir desculpas pelo problema causado, pedido reforçado através da utilização do adjetivo "sinceras". Além disso, novamente faz uso da máxima da simpatia, por agradecer o contato do cliente na exposição do problema, manifestando educação e cordialidade por ele. No trecho que segue, dizendo "vamos apurar e identificar a origem do erro e aperfeiçoar todos os procedimentos para que não haja uma nova ocorrência", o representante da empresa reclamada 
mantém a utilização da máxima da simpatia e também faz uso da estratégia de polidez positiva considere os interesses, vontades e necessidades do interlocutor e da estratégia de polidez positiva prometa, ofereça coisas, quando parece firmar um compromisso com o cliente em avaliar o problema, melhorando os serviços prestados.

Contudo, no trecho em que diz "Pedimos por gentileza de deixar a RECLAMAÇÃO NO SITE RECLAME AQUI EM ABERTO ATÉ QUE TUDO SEJA FINALIZADO", o representante, mesmo utilizando a palavra "gentileza", acaba perdendo sua face por romper com a estratégia de polidez negativa minimizar a imposição, ao fazer esse pedido utilizando a fonte em caixa alta, o que faz parecer que não está solicitando, mas, sim, ordenando, como se estivesse gritando para o cliente que espere e que não faça novas reclamações no site até que haja tempo para o problema ser totalmente solucionado. Ainda que tenha violado essa estratégia, acarretando na perda da sua face, o representante tenta resgatá-la ao dizer "Sempre que precisar, estaremos à sua inteira disposição", trecho que apresenta novamente o apelo à máxima da simpatia e estratégia de polidez positiva considere os interesses, vontades e necessidades do interlocutor, ao aparentemente mostrar boa vontade e disponibilidade para a prestação de futuros atendimentos ao cliente.

Possivelmente, podemos dizer que a ambivalência na fala desse participante se deu pelo seu interesse particular de não ser incomodado com novas reclamações, ao mesmo tempo em que precisava ser polido para não denegrir o nome da empresa, além do receio de ser demitido do seu cargo pelo mau atendimento prestado. Todavia, embora tenha recorrido mais aos recursos de polidez do que cometido violações desses recursos, notamos que houve prevalência da perda da sua face, visto que, nesses tipos de interação que são caracterizados por grandes conflitos e ameaças às faces, qualquer negligência como esta, mesmo que aparentemente pequena, pode ser determinante. Dessa forma, vemos que cliente e representante perderam suas faces por haver prevalência no rompimento, cada qual a seu modo e em proporções distintas, das estratégias e máximas de polidez analisadas.

\section{Análise 3}

Esta reclamação diz respeito ao defeito de um aparelho de celular comprado. Segundo o cliente, o aparelho apresentou mau funcionamento, o que motivou a reclamar com a empresa responsável pela venda do telefone: 
v. 7 (1)

$383-405$

jan/jun

2017

(5) "Tenho um celular RAZR I XT890 e hoje 03/06/2015 após a notificação que teria disponível a atualização para o Android 4.4.2 Kit Kat coloquei para atualizar. Mas logo após a instalação do sistema ele fica reiniciando sozinho apenas mostrando o logo da empresa X e não passa disso, o celular ficou inutilizável."

Em seguida, a resposta à reclamação:

(6) "Cliente X, tudo bem?

Conforme falei por telefone, tomamos as medidas necessárias para resolver o problema definitivamente. Peço desculpas pelos problemas e transtornos causados, pois esse não é o auto-atendimento empresa Y. Você tem a total liberdade em falar comigo por telefone ou mensagem privada, pois deixei meu numero para você em seu e-mail. Peço que me retorne urgente, para darmos continuidade, estarei a sua disposição até saber que está tudo bem.

Um grande abraço!

Aguardo o retorno!

Atenciosamente,

Representante da empresa Y."

Nessa situação, diferentemente das anteriores, em que os clientes reclamaram de uma maneira mais agressiva, este cliente opta por uma indiretividade e objetividade em sua reclamação, prevalecendo uma argumentação de teor mais expositivo do problema por meio de descrições, o que minimizou os riscos de perda de face, atenuando o grau de imposição e invasão da face do interlocutor, por não apresentar uma reclamação enfática sobre o problema do produto comprado, o que revela o respeito pelas estratégias de polidez negativa mostrar respeito e ser indireto. Considerando que se trata de outro contato com a empresa, que podemos inferir pela fala do representante "conforme falei por telefone", esse suposto segundo contato pode ter sido a causa do cliente reclamar de modo mais sutil, por ter passado por um suposto momento mais conflituoso e de alto grau de ameaça à sua face e à de seu interlocutor neste contato anterior mantido via telefone.

No caso do representante da empresa reclamada, notamos que também se preocupou em preservar a sua face e também a de seu cliente, 
utilizando várias estratégias de polidez tanto negativa, quanto positiva, além das máximas. De início, ao perguntar "Cliente x, tudo bem?", o representante da empresa solicitada faz uso da máxima da simpatia, demonstrando interesse pelo seu cliente, querendo saber se está tudo bem, utilizando, ainda, a estratégia de polidez positiva demonstre interesse, aprovação e simpatia pelo interlocutor, por aparentemente demonstrar preocupação e afeto pelo seu cliente. No momento em que diz "Peço desculpas pelos problemas e transtornos causados, pois esse não é $o$ auto-atendimento empresa $y$ ", o representante usa tanto estratégia de polidez negativa desculpar-se, ao pedir desculpas ao cliente pelos problemas ocasionados envolvendo a compra do telefone, como a máxima da concordância, quando busca minimizar as desavenças com o cliente, quando admite que o problema foi de fato causado pela empresa.

No trecho subsequente "você tem a total liberdade em falar comigo por telefone ou mensagem privada, pois deixei meu número para você em seu e-mail. Peço que me retorne urgente, para darmos continuidade, estarei a sua disposição até saber que está tudo bem", o representante usa mais uma vez a estratégia de polidez positiva demonstre interesse, aprovação e simpatia pelo interlocutor, máxima da simpatia, além de usar as máximas da generosidade e concordância, mostrando claramente o seu interesse em resolver o problema do cliente de forma amigável, o que se reforça por meio do uso da palavra "total", que marca a valorização da opinião do cliente. Ao final da resposta, o representante envia um abraço ("Um grande abraço!"), enfatizado por um ponto de exclamação e pelo adjetivo "grande", o que marca, com mais força, o uso da estratégia de polidez positiva em questão e, sobretudo, da máxima da simpatia, por tentar aproximar-se do seu cliente, demonstrando afeto e também um aparente carinho. Sendo assim, nesta interação vimos que cliente e empresa obtiveram sucesso na preservação das suas faces, pelo recorrente respeito e uso dos recursos de polidez.

\section{Conclusão}

Neste trabalho buscamos analisar como o ato de reclamar pode ameaçar as faces dos participantes envolvidos em uma interação virtual, tendo, por consequência, a perda da boa imagem social.

Primeiramente, observamos que nem todos os participantes se preocuparam em usar as estratégias e máximas de polidez na 
v. 7 (1)

383-405

jan/jun

2017

preservação das suas faces, havendo maior recorrência na perda de face na fala dos consumidores e maior tentativa de salvamento da face na fala dos representantes das empresas reclamadas. Vimos que os papeis sociais podem determinar a força ilocucionária dos atos de fala, e, sendo assim, podemos dizer que os representantes buscaram preservar com mais frequência as suas faces, devido às posições que possivelmente ocupam nas empresas (gerente de vendas, atendentes, assessores de relacionamento comercial, diretores comerciais etc), além da necessidade de não prejudicarem apenas a sua imagem pessoal, mas também a da empresa que representam.

Nas análises 1 e 2, vimos que os consumidores perderam suas faces e os representantes buscaram mantê-la, salvo na análise 2, na qual o representante, mesmo com o uso recorrente de algumas estratégias de polidez e máximas, por usar certos recursos gráficos de escrita que marcaram fortemente sua força ilocucionária resultando numa ordem direta, acabou perdendo sua face. Já na análise 3, vimos que o cliente e o representante da empresa foram igualmente polidos no tratamento oferecido um ao outro, salvando, assim, todas as faces envolvidas.

Ainda que não tenhamos esgotado o assunto e as análises, procuramos mostrar brevemente como a construção e ruptura da face estão diretamente relacionadas tanto ao uso, quanto à violação dos mecanismos de polidez. Nosso intuito não foi dizer quais categorias teóricas foram mais eficientes na aplicação ao corpus (se as estratégias de polidez propostas por Brown e Levinson ou as máximas por Leech), mas, sim, de entender que a polidez é um fenômeno que deve ser apreendido em sua amplitude.

Por fim, vale comentar que as interpretações contidas nas análises foram apenas um olhar lançado ao corpus, uma proposta de estudo que está passível de rediscussão. Desse modo, esperamos que os resultados apreendidos neste breve trabalho possam corroborar para os estudos linguísticos em pragmática, abrindo espaço para novas discussões e aprimoramentos acerca do tema escolhido.

\section{Referências}

BROWN, Penelope; LEVINSON, Stephen. C. Politeness: some universals in language usage. Cambridge: Cambridge University Press. 1987.

CHARAUDEAU, Patrick; MAINGUENEAU, Dominique. Dicionário de análise do discurso. São Paulo: Contexto, 2004. 
GALEMBECK, Paulo de Tarso. O turno conversacional. In: PRETI, D. (org.) Análise de textos orais. São Paulo: FFLCH/USP, 1993. p. 55-80.

GOFFMAN, Erving. A elaboração da face. Uma análise dos elementos rituais da interação social. In: Figueira, S. (org). Psicanálise e ciências sociais. Trad. I. Russo. Rio de Janeiro: Francisco Alves, 1980, p. 76-114.

Footing. In: RIBEIRO, B.T.; GARCEZ, P.M. (orgs.). Sociolinguística interacional. 2. ed. São Paulo: Loyola, 1967 [2002].

GRICE, Paul. Lógica e conversação. In: DASCAL, Marcelo (org). Fundamentos metodológicos da lingüística. Pragmática. vol. IV. Campinas: Ed do autor, 1982.

KOCH, Ingedore Grunfeld Villaça. A inter-ação pela linguagem. São Paulo: Contexto, 1992.

LA TAILLE, Yves de. Desenvolvimento moral: a polidez segundo as crianças. Cad. Pesqui., São Paulo, n. 114, p. 89-119, nov. 2001. Disponível em: <http://publicacoes.fcc.org.br/ojs/index.php/cp/ article/view/585/584 >. Acesso em: 1 mai. 2015.

LEECH, Geoffrey. Principles of Pragmatics. New York: Longman, 1983.

MARCONDES, Danilo. Filosofia, linguagem e comunicação. São Paulo: Contexto, 1992.

OLIVEIRA, Jair A. de. Polidez e identidade: a virtude do simulacro. Biblioteca on-line de ciências da comunicação, 2005. Disponível em: <http://www.bocc. ubi.pt/pag/oliveira-jair-polidez-identidade.pdf>. Acesso em: 10 jun. 2015.

RECLAMEAQUI. Reclamações atendidas. Disponível em: <http://www. reclameaqui.com.br/>. Acesso em: 1-24 jun. 2015.

RECLAMEAQUI. Net sem sinal constantemente. Disponível em:<http:// www.reclameaqui.com.br/13144817/net-servicos -tv-banda-larga-etelefone/net-sem-sinal-constatemente/>. Acesso em: 1-24 jun. 2015.

RECLAMEAQUI. Celular travou após atualização do android Kit Kat. Disponível em: <http://www.reclameaqui.com.br/13297615/motorola-do-brasil/celulartravou-apos-atualizacao-do-android-kit-kat/> Acesso em: 1-24 jun. 2015.

RECLAME AQUI. Atraso no envio e dificuldade para efetivar troca. Disponível em: <http://www.reclameaqui.com.br/13310892/netshoes/atraso-no-envioe-dificuldade-para-efetivar-troca/>. Acesso em: 1-24 jun. 2015.

Recebido em: 07 de fev. de 2017.

Aceito em: 24 de ago. de 2017. 